\title{
Pattern and Risk Factors of Neural Tube Defects, Khartoum-Sudan
}

\author{
Mohammed Omer I ${ }^{1 *}$, Mohammed N I ${ }^{1}$, Mohammed Abdullah $\mathbf{O}^{2}$ and Ahmed Abbasher $\mathrm{L}^{2}$ \\ ${ }^{1}$ Department of Paediatrics and Child Health-Faculty of Medicine -University of Khartoum, Sudan \\ ${ }^{2}$ Soba University Hospital, Sudan
}

Submission: December 22, 2020; Published: February 04, 2021

*Corresponding author: Mohammed Omer I, Department of Pediatrics and Child Health-Faculty of Medicine -University of Khartoum, Sudan

\begin{abstract}
Background: Neural tubes defects (NTDs) are abnormalities that occur during neurulation, which result in birth defects of the brain spine or spinal cord. They are due to multifactorial etiology, amongst which are genetic and environmental factors.

Methods: This is a cross -sectional- case control study, conducted at Khartoum state in a one-year time, and aimed to identify the pattern and risk factors of NTDs. All newborns with any type of neural tube defect admitted to NICU in study area during the study period were selected. Data was collected using a questionnaire covering medical, social history and clinical examination.

Results: Out of the 36785 delivered newborns during the study period, 103 had NTD. The types of NTDs include myelomeningocele 47(45.7\%), anencephaly 18(17.5\%), encephalocele 14(13.6\%), myelomeningocele + hydrocephalus $11(10.7 \%)$ and meningocele $8(7.8 \%)$. Family history of NTDs was found in 11(10.7\%) of the affected newborns siblings. Only about one third of the studied mothers received folic acid during pregnancy. Other risk factors include two (1.9\%) of the mothers exposed to irradiation and hyperthermia each, and 7(6.8\%) exposed to anti-epileptic drugs, Diabetic mothers were $12(11.7 \%)$. Positive family history of neural tube defects was found in $11(10.7 \%)$ affected newborns. $74.5 \%$ of the studied families were of low social class.
\end{abstract}

Conclusion: The commonest types of NDTs among the studied newborns were myelomeningocele followed by anencephaly

The most common risk factors of NTDs among the study group include low and irregular folic acid intake during pregnancy, previous family history, maternal diabetes and low social class.

Keywords: Neural tube defect; Newborns; Genetic; Pregnancy

Abbreviations: NTD: Neural Tube Defects; NICU: Neonatal Care Units; SPSS: Statistical Packages for Social Sciences; MTHFR: Methylenetetrahydrofolate Reductase; RFC: Reduced Folate Carrier Protein

\section{Background}

Neural tube defects (NTD) are the second most prevalent congenital anomaly in the United States, second only to cardiac malformations, and they are associated with substantial morbidity and mortality.

The embryology of the neural tube development has been studied extensively and is well understood. In contrast, the mechanisms which lead to NTDs, as well as the variation in anatomical location and severity of these defects, are not well understood Genetic and environmental factors have been found to cause these defects, both individually and in combination [1].
Environmental risk factors are thought to play a role in NTD development, but few have been consistently replicated in human studies. Among these, randomized controlled trials indicated that folic acid supplementation could prevent at least one half of all NTDs and, as a result, folic acid fortification of enriched grains became mandatory in the United States in 1998; subsequently, NTD rates decreased by an estimated $26 \%$ [2].

Maternal exposure to certain teratogens has also been documented to increase the risk for NTDs. Two anticonvulsant medications in current use, valproic acid, and carbamazepine, 
have been demonstrated to be risk factors in several studies. Valproic acid is associated with NTDs in 1-2\% of exposed children [3].

Recognized risk factors associated with NTDs include maternal diabetes, which causes NTDs, as well as other birth defects, by disrupting expression of genes that control essential developmental processes [4,5].

Hyperthermia is a potent NTD-causing teratogen in rodents, and NTDs following episodes of maternal fever or extreme sauna usage in early pregnancy have been reported. Maternal "flu" in the first trimester has also been implicated [6].

Consanguinity was a significant risk factor for the development of NTDs in the report of Murshid from Al Madina, Saudia [7].

\section{Methods}

a. Study Design: This is a cross-sectional- case control study, conducted in Khartoum state in a one-year time, and aimed to identify the pattern and risk factors of NTDs.

b. Study Area: The study was conducted at the two main neonatal care units (NICU) in Khartoum state which are Soba University Hospital NICU and Omdurman Maternity hospital.

c. Soba University Hospital: located $15 \mathrm{~km}$ south of the center of the capital of Sudan, Khartoum, and considered the largest training hospital for the students of the faculty of medicine, University of Khartoum. The NICU accommodates 25 babies. The turnover is about 800-1000. babies per year. The obstetrics and gynecology department at SUH is one of the main referral centers for high risk pregnancies, the fetal unit in the hospital receives the referred critical pregnancies from all over the country.

d. Omdurman Maternity Hospital: was established in 1957 as the first specialized hospital in the country, to provide care and medical services to mothers and newborns babies. The hospital serves all the surrounded rural areas and even the nearby towns. The NICU department accommodates about 75babies. The turnover is about 4000-5000 babies per year.

e. Study population: Total coverage of all newborns with neural tube defects who were admitted to the NICU of the two hospitals during the study period.

f. Exclusion Criteria: Newborns with NTDs born at home or in other hospitals were not included.

Case control group was chosen from mothers delivered at the same hospitals and had normal children. Data was collected using structured questionnaire.

\section{g. Statistical analysis}

Collected data was analyzed using a master sheet and excel computer program, Statistical Packages for Social Sciences (SPSS). Data was then presented in the type of appropriate figures and tables.

\section{Results}

The total number of the infants delivered during the study period was 36785, of whom 103 newborns had NTDs, giving a prevalence rate of 2.8 in 1000 live birth. The male to female ratio was $1.5: 1$. The common types of NTDs was myelomeningocele in $49(47.7 \%)$, followed by anencephaly $18(17.5 \%)$, encephalocele $14(13.6 \%)$, myelomeningocele and hydrocephalus 11(10.7\%) and meningocele $8(7.8 \%)$ as shown in Table 1.

Table 1: Classification of neural tube defect among study group ( $\mathrm{n}=103)$.

\begin{tabular}{|c|c|}
\hline Types & N (\%) \\
\hline Myelomeningocele & $49(47.7)$ \\
\hline Anencephaly & $18(17.5)$ \\
\hline Encephalocele & $14(13.6)$ \\
\hline Meningocele & $08(7.8)$ \\
\hline Spina bifida occulta & $02(1.9)$ \\
\hline Myelomeningocele +Hydrocephalus & $11(10.7)$ \\
\hline Meningocele +cleft lip + palate & $01(1.0)$ \\
\hline Total & $103(100.0)$ \\
\hline
\end{tabular}

The majority $42(40.8 \%)$ of the mothers were in the age group 25 - 30 years. $72(68.9 \%)$ of the mothers were multipra, 12(11.7\%) were grandmultipra and 20(19.4\%) were primigravida. Two (1.9\%) mothers work as an X-ray technician and another two (1.9\%) work as tea sellers. $7(6.8 \%)$ of the mothers were on antiepileptic drugs (carbamazepine and sodium valproate). $12(11.7 \%)$ mothers had diabetes mellitus (DM) of whom three had gestational diabetes. Eight of them were on insulin, three on diet control and one on oral hypoglycemic management. $49(47.6 \%)$ mothers had fever during pregnancy. $11(10.7 \%)$ of the affected newborns had a sibling with neural tube defect of whom $6(54.5 \%)$ had anencephaly, 2(18.2\%) hydrocephalus, 1(9.1\%) patient, had myelomeningocele meningocele, hydrocephalus and spina bifida.

Sixty-eight (66\%) mothers started folic acid supplementation after conception, of whom 36(54.5\%) started supplementation in the first trimester. 35(34\%) mothers did not receive folic acid supplementation throughout pregnancy.

Seventy-six (73.8\%) patients were referred to pediatric surgery or neurosurgery departments. $60 \%$ underwent immediate surgical interventions. $27(26.2 \%)$ died before surgery with possible sepsis.

There is no statistical significant difference between the mothers of children with NTDs and the control group regarding maternal age (P- Value more than 0.05). However, there is statistical significant increased risk of having a baby with NTDs among mothers with Diabetes Mellitus, history of fever during pregnancy, sibling with NTDs and those of low socioeconomic status.

Regarding folic acid supplementation, it was found that there is statistical significant increased risk of having a baby born 


\section{Global Journal of Intellectual \& Developmental Disabilities}

with NTDs among mothers who had no supplementation at all, supplementation started after conception and those who start supplementation after first trimester ((P- Value more than 0.05) as shown in Table 2.

Table 2: Folic acid supplements in the study \& control groups (case=103, control =88).

\begin{tabular}{|c|c|c|c|}
\hline \multirow{2}{*}{ Folic acid Supplementation } & Cases & Control \\
\cline { 2 - 4 } & $\mathrm{N}(\%)$ & $(\%)$ & \multirow{2}{*}{ P value } \\
\hline Received folic acid & $68(66.0)$ & $67(76.1)$ & \\
\hline Not Received folic acid & $35(34.0)$ & $21(23.9)$ & 0.04 \\
\hline Preconception & $02(2.9)$ & $07(10.4)$ & 0.04 \\
\hline After conception & $66(97.1)$ & $55(82.1)$ & \multirow{2}{*}{} \\
\hline
\end{tabular}

\section{Discussion}

The pattern and risk factors were assessed in 103 newborns with NTDs. Females slightly predominated and this was similarly reported in several studies. [8,9] The commonest type of NTDs identified in this study was myelomeningocele $(47.6 \%)$ followed by anencephaly and encephalocele $(17.5,13.6 \%)$ respectively. This was similarly reported by Mohammad AL-Qudah and his college at Prince Rashid Bin Al-Hassan Hospital, who reported myelomeningocele in (45.7\%) of the studied newborns, followed by anencephaly (17.5\%), encephalocele (13.6\%), myelomeningocele \& hydrocephalus $(10.7 \%)$ and meningocele $(7.8 \%)[10]$.

In this study the possible risk factors for NTDs were tested using a control group, lack of folic acid supplementation was found to significantly increase the risk of having a baby born with NTDs among mothers who had no supplementation at all, or supplementation started after conception and in those who started supplementation after the first trimester. Yet, the exact mechanism of how folic acid prevents NTDs is not clear. Folic acid may not reduce NTD risk to the same degree in all racial/ethnic groups, suggesting that a genetic component may be involved [11]. De Marco et al. [12] suggest that the influence of folic acid use may relate to defects in homocysteine metabolism such as mutations in the methylenetetrahydrofolate reductase (MTHFR) gene. The same study observed an association between reduced folate carrier protein (RFC) gene polymorphism and NTD risk. Studies by Czeizel, et al. [13] and Kirke et al. [14] showed that the biochemical profile of women who have had pregnancies affected by NTDs shows not only a low concentration of serum folate, but also an elevated concentration of homocysteine and methylmalonic acid, and a reduced concentration of vitamin B12. This suggests that an abnormality of folate metabolism, rather than a simple nutritional deficiency, is present. In addition, amniotic fluid levels of homocysteine are abnormally high when the fetus has a NTD, suggesting that a subset of NTDs could be due to a primary or secondary maternal or fetal derangement of homocysteine metabolism $[13,14]$.
The maternal age was not found to have significant effect on the increased probability of having a child with NTDs. However, a number of studies have reported maternal age as a risk for NTDs to be of U-shaped, highest among youngest and oldest women, while Owen et al and Hendricks, et al. $[15,16]$ found that the risk decreases with increasing maternal age. The majority (68.9\%) of mothers were multipara which was similarly reported by Whiteman, et al [17].

The risks for NTD include exposure to radiation, as two (1.9\%) of the mothers were exposed to radiation through their work as X-ray technicians, the same percentage were exposed to hyperthermia as their jobs as tea sellers expose them to long periods of work under sun heat on the streets, which sometimes approach 500C.These two risk factors need to be further studied as the sample size was relatively small. The same findings reported by Liao, et al. [18] on the association between NTDs and parental occupation, he reported increased odds ratios associated with both maternal and paternal occupations. These included agriculture, cleaning, welding, transport, healthcare occupations (nursing, dentistry), and painting (paternal). In China, living near coal mines is a significant environmental risk factor for the development of NTDs. Also, several studies have reported that NTDs occurred more frequently among children born to women of lower socioeconomic status. This has been observed in North America, Europe, and several other regions. Another study in Nigeria done by Bankole, et al. [19] showed that seventy-three percent of mothers of affected children were from a low socio-economic class. In this study it was found that there is significant increased risk of NTDs among patients of low socioeconomic background (73.8\%) compared to (35.2\%) among the control group with a significant $p$ value of 0.001 . Wasserman, et al. [20] explained that people from low socioeconomic class are vulnerable to hyperthermia in such hot areas as they lack cooling facilities and usually work under the sun.

Seven of the mothers (6.8\%) were on anti-epileptic treatment (carbamazepine and sodium valproate) during pregnancy. This agreed with the study done by Seidahmed, et al. [21] which 
showed that maternal exposure to certain teratogens has also been documented to increase the risk for NTDs. Two anticonvulsant medications in current use, valproic acid, and carbamazepine, have been demonstrated to be risk factors in several studies. Valproic acid is associated with NTDs in 1-2\% of exposed children, as well as urogenital, craniofacial, and cardiac malformations.

Twelve (11.7\%) of the studied mothers had Diabetes mellitus which was found significantly to increase the risk of NTDs while none of the mothers of the control group had DM. Studies by Janssen, et al and Ramos-Arroyo, et al. [22,23] suggest similar findings, although Aberg, et al. [24] reported no association between maternal diabetes and NTDs.

Family history of a previous sibling with neural tube defects was found in $11(10.7 \%)$ of the affected newborns which represents a significant risk factor, compared to none among the control group which is a significant difference between the two groups $(\mathrm{P}=0.002<0.05)$. Anencephaly was the most reported type among siblings. This is similar to the study done by Detrait, et al., who stated that two key points that suggest a genetic influence on the development of NTDs are their association with specific syndromes and other physical defects and the high rate of recurrence in siblings. A close examination of family history usually shows that there are/were other affected family members However, the inheritance pattern is still unclear [1].

Forty-nine (47.6\%) of the mothers experienced fever during pregnancy. This agreed with Shaw, et al. [25] who showed that fever or use of saunas and hot tubs, has been linked to increased risk of NTDs, particularly spina bifida, although the results are not consistent.

Although consanguinity was reported to be a risk factor for NTDs, we didn't consider it, as it is high (64\%) among both patients and the control group. In a Saudi study by Murshid, (89\%) of the spina bifida parents were consanguineous compared with $67 \%$ of the controls $(\mathrm{p}<0.0005)$ [7].

\section{Conclusion}

The commonest types of NDTs among the studied newborns were myelomeningocele followed by anencephaly.

The most common risk factors of NTDs among the study group include low and irregular folic acid intake during pregnancy, previous family history, maternal diabetes and low social class.

What is already known on this topic:

- $\quad$ NTDs are common congenital malformation.

- The underlying risk factors are multifactorial.

- NTDs are associated with lack of folic acid supplementation during pregnancy.

What is the study adds:
- Maternal age is not statistically related to NTDs.

- Myelomeningeocoele is the commonest revealed type.

- $\quad$ The relation of hyperthermia and NTDs needs further studies.

\section{Acknowledgements}

We are thankful to the hospital administrations for giving permission to conduct the research. We are very grateful to all the mothers for their collaboration and allowing us to use both their and newborns data. We are very grateful to any person who contributed to this research.

\section{References}

1. Detrait RE, George TM, Etchevers HC, Gilbert JR, Vekemans M, et al (2005) Human neural tube defects: developmental biology, epidemiology, and genetics. Neurotoxicol Teratol 27(3): 515-524.

2. MMWR Morb Mortal Wkly Rep (2004) Center for Disease Control and Prevention. Spinabifida and anencephaly before and after folic acid mandate--United States, 1995-1996 and 1999-2000. 53(17): 362-365.

3. Seidahmed MZ, Miqdad AM, Al-Dohami HS, Shareefi OM (2009) A case of fetal valproate syndrome with new features expanding the phenotype. Saudi Med J 30(2): 288-291.

4. Mills JL (2010) Malformations in infants of diabetic mothers. Teratology 25: 385-394.Birth Defects Res A Clin Mol Teratol 88(10): 769-778.

5. Loeken M (2004) Free radicals and birth defects. J Matern Fetal Neonatal Med 15(1): 6-14.

6. Moretti ME, Bar-Oz B, Fried S, Koren G (2005) Maternal hyperthermia and the risk for neural tube defects in offspring: systematic review and meta-analysis. Epidemiology 16(2): 216-219.

7. Murshid WR (2000) Spina bifida in Saudi Arabia: is consanguinity among the parents a risk factor? Pediatr Neurosurg 32(1): 10-12.

8. De-Regil LM, Fernández-Gaxiola AC, Dowswell T, Pena-Rosas JP (2010) Effects and safety of periconceptional folate supplementation for preventing birth defects. Cochrane Database Syst Rev 10(2): 79-85.

9. US Preventive Services Task Force (2009) Folic acid for the prevention of neural tube defects: US Preventive Services Task Force recommendation statement. Ann Intern Med 150(9): 626-631.

10. Mohammad AL-Qudah, Yousif Taha, Mahmoud El Khateeb, Sulthan Q Md, Ghassan Q MD, et al. (2010) Neural Tube Defects at Prince Rashid Bin Al-Hassan Hospital in Irbid-Jordan. JRMS 17(4): 24-27.

11. Suarez L, Hendricks KA, Cooper SP, Sweeney AM, Hardy RJ, et al. (2000) Neural tube defects among Mexican Americans living on the US-Mexico border: effects of folic acid and dietary folate. Am J Epidemiol 152(11): 1017-1023.

12. De Marco P, Calevo MG, Moroni A, Arata L, Merello E, Ca A, et al. (2001) Polymorphisms in Genes Involved in Folate Metabolism as Risk Factors for NTDs. Eur J Pediatr Surg 11(1): S14-S17.

13. Czeizel AE, Dobó M, Vargha P (2004) Hungarian cohort-controlled trial of periconceptional multivitamin supplementation shows a reduction in certain congenital abnormalities. Birth Defects Res A Clin Mol Teratol 70(11): 853-861.

14. Kirke PN, Mills JL, Molloy AM, Brody L, Mary C, et al. (2004) Impact of the MTHFR C677T polymorphism on risk of neural tube defects: casecontrol study. BMJ 2004; 328(7455):1535-1536. 
15. Owen TJ, Halliday JL, Stone CA (2000) Neural tube defects in Victoria Australia: potential contributing factors and public health implications. Aust N Z J Public Health 24(6): 584-589.

16. Hendricks KA, Simpson JS, Larsen RD (1999) Neural tube defects along the Texas-Mexico border, 1993-1995. Am J Epidemiol 149(12): 11191127.

17. Whiteman D, Murphy M, Hey K, O’Donnell M, Goldacre M (2000) Reproductive factors, subfertility, and risk of neural tube defects: a case-control study based on the Oxford Record Linkage Study Register Am J Epidemiol 152(9): 823-828

18. Liao Y, Wang J, Li X, Guo Y, Zheng X (2009) Identifying environmental risk factors for human neural tube defects before and after folic acid supplementation. BMC Public Health 9(391): 1-9.

19. Bankole OB, Arigbabu SO, Kanu OO (2012) Spinal neural tube defects in Lagos University Teaching Hospital, Nigeria. Nig Q J Hosp Med 22(1) 22-24.

20. Wasserman, Shaw M, Gould I, Syme SL (1998) Socioeconomic status, neighborhood social conditions, and neural tube defects. Am J Public Health 88(11): 1674-1680.
21. Seidahmed MZ, Abdelbasit OB, Shaheed MM, Alhussein KA, Miqdad AM, et al. (2014) Epidemiology of neural tube defects. Saudi Med J 35(Suppl 1): S29-S35.

22. Janssen PA, Rothman I, Schwartz SM (1996) Congenital malformations in newborns of women with established and gestational diabetes in Washington State, 1984-1991. Paediatr Perinat Epidemiol 10(1): 52 63.

23. Ramos-Arroyo MA (1991) Birth defects in twins: study in a Spanish population. Acta Genet Med Gemellol (Roma) 40(3-4): 337-344.

24. Aberg A, Westbom L, Kallen B (2001) Congenital malformations among infants whose mothers had gestational diabetes or pre existingdiabetes. Early Hum Dev 61(2): 85-95.

25. Shaw GM, Lammer EJ, Zhu H, Baker MW, Neri E, et al. (2002) Maternal periconceptional vitamin use, genetic variation of infantreduced folate carrier (A80G), and risk of spina bifida. Am J Med Genet 108(1): 1-6.

\section{Your next submission with Juniper Publishers will reach you the below assets}

- Quality Editorial service

- Swift Peer Review

- Reprints availability

- E-prints Service

- Manuscript Podcast for convenient understanding

- Global attainment for your research

- Manuscript accessibility in different formats

( Pdf, E-pub, Full Text, Audio)

- Unceasing customer service

Track the below URL for one-step submission https://juniperpublishers.com/online-submission.php 
